\title{
Canaloplasty in the Treatment of Open-Angle Glaucoma: A Review of Patient Selection and Outcomes
}

\author{
Ivano Riva - Paolo Brusini - Francesco Oddone - Manuele Michelessi • \\ Robert N. Weinreb · Luciano Quaranta
}

Received: October 3, 2018 / Published online: November 28, 2018

(C) The Author(s) 2018

\begin{abstract}
Canaloplasty is a relatively new non-penetrating surgery for the reduction of intraocular pressure in patients affected by glaucoma. The technique uses a microcatheter to perform a 360 - cannulation of Schlemm's canal and leaves in place a tension suture providing an inward distension. It aims to restore the physiological outflow pathways of the aqueous humour and is independent of external wound healing. Several studies have shown that canaloplasty is effective in reducing intraocular pressure and has a low rate of complications, especially compared
\end{abstract}

Enhanced digital features To view enhanced digital features for this article go to https://doi.org/10.6084/ m9.figshare.7321406.

I. Riva $\cdot$ F. Oddone $\cdot$ M. Michelessi

IRCCS, Fondazione Bietti, Rome, Italy

P. Brusini

Department of Ophthalmology, "Città di Udine"

Health Center, Udine, Italy

R. N. Weinreb

Hamilton Glaucoma Center and Shiley Eye

Institute, University of California San Diego,

San Diego, CA, USA

\section{Quaranta $(\bowtie)$}

Department of Medical and Surgical Specialties,

University of Brescia, Brescia, Italy

e-mail: luciano.quaranta@unibs.it with trabeculectomy, the gold standard for glaucoma surgery. Currently, canaloplasty is indicated in patients with open-angle glaucoma, having a mild to moderate disease, and the combination with cataract phacoemulsification may provide further intraocular pressure reduction. This article reviews canaloplasty indications, results and complications and analyses its outcomes compared with traditional penetrating and non-penetrating techniques.

Keywords: Canaloplasty; Deep sclerectomy; Glaucoma; Ophthalmology; Phaco-canaloplasty; Trabeculectomy; Viscocanalostomy

\section{INTRODUCTION}

Glaucoma is one of the leading causes of blindness worldwide [1]. Primary open-angle glaucoma (POAG), the most common type of glaucoma in white populations [2], has a typically chronic course, characterized by progressive damage to the optic disc and visual field deterioration [3, 4]. Although several risk factors for glaucoma have been investigated [5-9], reduction of intraocular pressure (IOP) remains the mainstay of glaucoma treatment as studies have clearly shown a positive effect of IOP reduction on both glaucoma development and progression [10-16]. 
The first approach in reducing IOP generally consists of topical medications. However, when target IOP is not achievable or progression is detected in spite of maximum tolerated medical therapy, surgery is advisable [17, 18]. Trabeculectomy (TRAB) is actually the gold-standard procedure for glaucoma surgery. However, it is plagued by a major rate of intra- and postoperative complications, such as choroidal haemorrhage $[19,20]$, cataract development [21], hypotony [22, 23], bleb leakage [24, 25] and infections [26]. These complications are largely due to the creation of a patent communication between the anterior chamber and subconjunctival space as a full thickness sclerotomy is performed during the procedure (i.e., penetrating surgery). To reduce these complications, non-penetrating surgeries have been proposed [27]. In these procedures there is no direct communication between the anterior chamber and extraocular spaces. For this reason they are considered safer than TRAB at the cost of lower hypotensive efficacy [27, 28]. Deep sclerectomy (DS), a non-penetrating procedure, creates a trabeculo-descemetic window through which aqueous humour (AH) slowly leaks from the anterior chamber [29]. Viscocanalostomy (VC), another non-penetrating procedure, aims to restore the physiological $\mathrm{AH}$ filtration pathway, expanding Schlemm's canal by means of the viscoelastic substance [30].

Canaloplasty (CP) is a relatively new nonpenetrating technique and can be considered a technical amelioration of VC. Described in 2005 by Kearney et al., it uses a breakthrough microcatheter technology to restore the physiological AH outflow system [31]. Clinical studies have shown that $\mathrm{CP}$, performed alone or in conjunction with cataract extraction, reduces IOP significantly and in the long term, with an excellent safety profile. The objective of this review is to describe the CP surgical technique, its indications and the results in terms of the hypotensive efficacy and safety profile. This article is based on previously conducted studies and does not contain any studies with human participants or animals performed by any of the authors.

\section{PATIENT SELECTION}

CP is mainly indicated in patients affected by POAG when IOP is not satisfactorily controlled with medical therapy or medications are not tolerated [32, 33]. Patients affected by pigmentary glaucoma or pseudoexfoliative glaucoma are candidates for this surgery as well as long as the irido-corneal angle is open and easily accessible. A few reports have described the use of CP in patients affected by juvenile glaucoma [34] and in some phenotypes of secondary glaucoma, such as steroid-induced glaucoma [35] or glaucoma secondary to uveitis [36]. An exploratory indication for CP may be in patients with a previous failed TRAB when gonioscopic examination reveals an intact Schlemm's canal $[37,38]$ or even in case of a disrupted canal wall [39, 40] (Fig. 1).

Careful evaluation of patient's clinical characteristics is always mandatory when selecting a surgical procedure. Patients with moderate/high IOP and without advanced visual field and/or optic disc damage probably benefit more from $\mathrm{CP}$ as extremely low IOPs are not required. The absence of a filtration bleb and its non-penetrating nature make CP particularly attractive for patients at high risk of infections or choroidal bleeding, with enhanced wound healing or with complications from a previous TRAB in the contralateral eye [41]. Finally, young

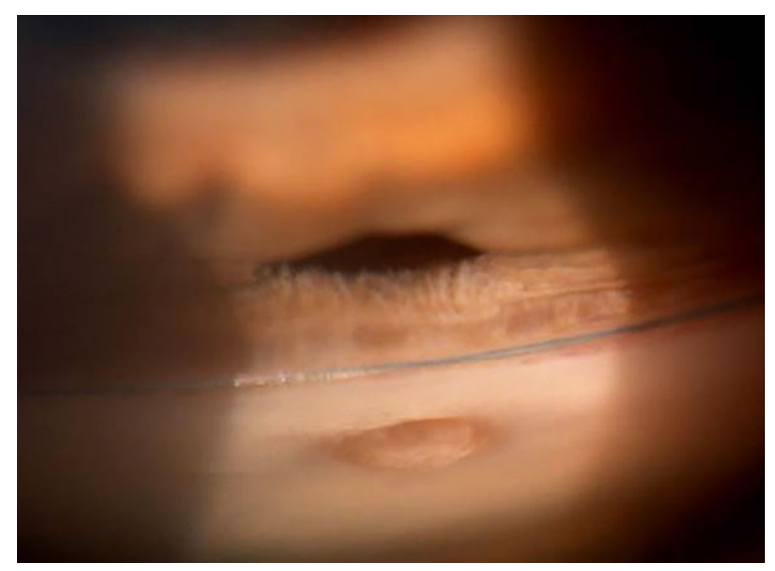

Fig. 1 Gonioscopic image of a canaloplasty performed after trabeculectomy: Prolene suture in place 
patients with moderate IOP and used to contact lens wearing may benefit from this bleb-less procedure.

Contraindications are angle-closure glaucoma, post-traumatic glaucoma with angle recession and almost all the secondary glaucomas (neovascular glaucoma, aphakic glaucoma, etc.) with the exceptions already described [42]. Angle closure is a contraindication for canaloplasty, mainly for two reasons: (1) persistent irido-trabecular contact results in a progressive process of Schlemm's canal endothelial damage and Schlemm's canal occlusion, making the microcatheter passage not easily achievable [43]; (2) irido-trabecular contact and peripheral anterior synechiae block AH outflow anteriorly to Schlemm's canal, damaging the trabecular meshwork and increasing resistance at this level [43]. Patients with narrow angles or plateau iris may benefit from this technique when performed in combination with cataract extraction as tensioning the suture may result in further narrowing of the angle.

\section{SURGICAL PROCEDURE}

Sub-conjunctival or peri-bulbar anaesthesia is generally performed, but general anaesthesia could sometimes be preferred in young patients and in myopic eyes. A 4-0 suture under the superior rectus muscle insertion or a corneal bridle suture may be placed to better expose the surgical field and rotate the eye inferiorly. Conjunctiva and Tenon's capsule are gently dissected, creating a fornix-based flap, usually at 12 o'clock position. Differently from TRAB, it is advisable to avoid cauterization, preserving episcleral vessels. Topical vasoconstrictor agents may be used. A superficial scleral flap is dissected, carrying forward the incision up to clear cornea (Fig. 2a). The shape of the superficial flap may vary, according to the surgeon's experience and preferences (generally a parabolic flap is created). However, flap thickness should be approximately fixed to one third of the total scleral thickness $(200-250 \mu \mathrm{m})$. A smaller and deeper scleral flap is then sculpted just above the choroidal plane and extended forward to slice the scleral spur (Fig. 2b). In this way,
Schlemm's canal is opened and a trabeculo-descemetic window is created. A gentle pressure at the level of the Schwalbe line, using a cellulose sponge, may help further extend the trabeculodescemetic window, encouraging $\mathrm{AH}$ leaks. At this point, the internal wall of Schlemm's canal should be removed with micro-surgical forceps. The deep flap is then dissected away, and the two ostia of Schlemm's canal are exposed (Fig. 2c).

Repeated visco-dilatation of the ostia with a microcannula is performed (Fig. 2d). The microcatheter (iTrack 250, Ellex iScience, Inc., Freemont, CA, USA) has a $250 \mu \mathrm{m}$ diameter and an embedded optical fibre connected to a laser flickering red light source for easy identification of the distal tip through the sclera. The microcatheter is inserted into Schlemm's canal through the exposed ostia and advanced throughout the $360^{\circ}$ (Fig. 2e). When the distal tip of the catheter emerges at the opposite site, a 10-0 Prolene suture is tied to the tip, and the microcatheter is withdrawn, injecting approximately $0.5 \mu \mathrm{l}$ of viscoelastic material every $2 \mathrm{~h}$ (Fig. 2f). A high-weight molecular viscoelastic agent is preferred during this phase. Viscodilation of Schlemm's canal is an essential part of the procedure as it breaks adhesion inside the canal, stretches the trabecular plates by means of micro-perforations into the inner wall of the trabecular meshwork and separates herniations of the inner wall of the trabecular meshwork into the outer wall collector channels. The tip is then extracted from Schlemm's canal at the initial surgical site, and the suture is knotted under tension to obtain an inward distension of the trabecular meshwork (Fig. 2g). High-resolution UBM may be used in this phase, if available, to evaluate the tension of the suture and the dilatation of Schlemm's canal. Finally, the superficial scleral flap is tightly closed with several Vicryl or nylon stitches to ensure a watertight closure, and the conjunctival flap is sutured (Fig. 2h). Postoperative treatment consists of antibiotic drops for a week and local steroids or nonsteroidal anti-inflammatory drops for a period of 4-6 weeks, according to the surgeon's habits and patient's course. 

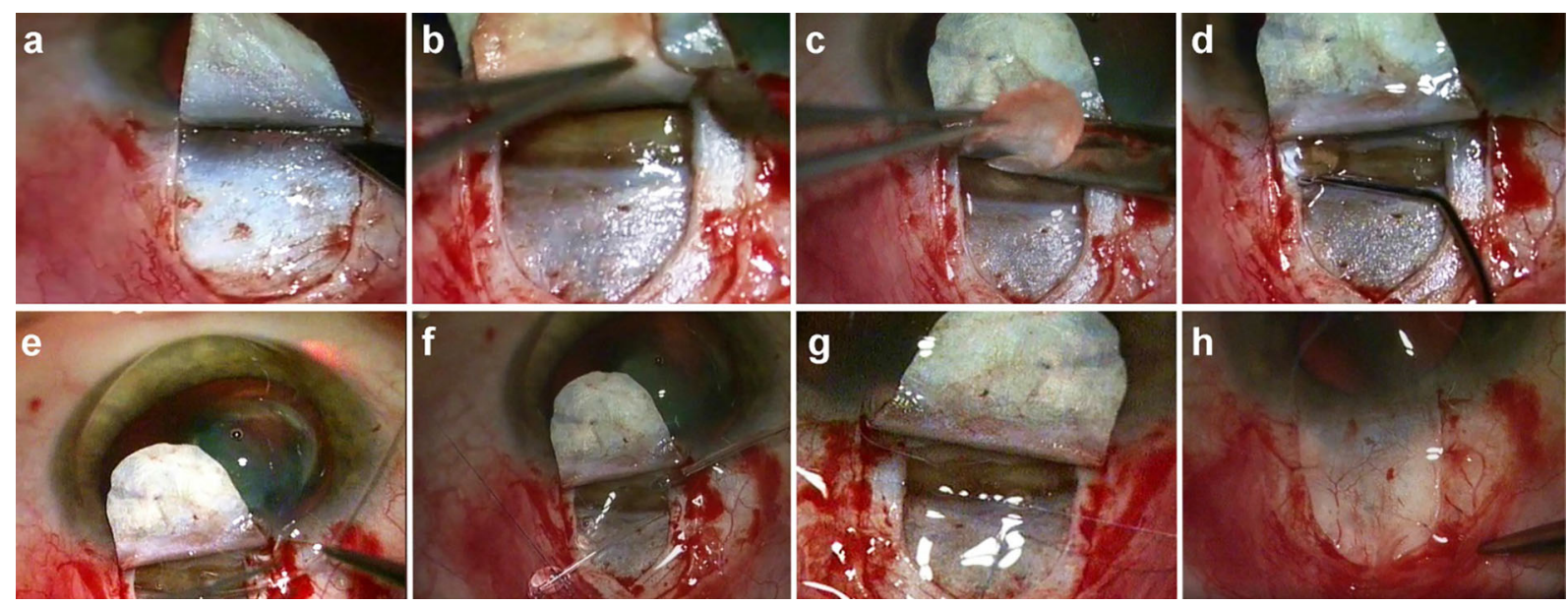

Fig. 2 Canaloplasty surgical technique. a Dissection of the superficial scleral flap; $\mathbf{b}$ creation of a deep scleral flap; c cutting of the deep scleral flap and exposure of Schlemm's canal ostia; d viscodilation of Schlemm's canal

\section{ADVERSE EVENTS}

$\mathrm{CP}$ is a safe procedure, and complications, both intra- and postoperative, are generally mild (Table 1) [32,33]. While intraoperative complications decrease with the surgeon's experience and after a long learning curve, postoperative

Table 1 Frequency of canaloplasty-related adverse events

\begin{tabular}{ll}
\hline Adverse event & $\begin{array}{l}\text { Frequency } \\
(\%)\end{array}$ \\
\hline $\begin{array}{l}\text { Intraoperative complications } \\
\text { Rupture of trabeculo-descemetic } \\
\text { membrane }\end{array}$ & $1.8-8.5$ \\
Schlemm's canal cannulation not & $7.3-26$ \\
possible & \\
Descemet's membrane detachment & $1.6-9.1$ \\
Postoperative complications & \\
Hyphaema/microhyphaema & $6.1-85.2$ \\
IOP spike & $1.6-30$ \\
YAG-laser goniopuncture & $0-22$ \\
Cataract formation & $0-8.4$ \\
Suture extrusion & $0-6.7$ \\
\hline
\end{tabular}

ostia with a microcannula; e advancement of the microcatheter through Schlemm's canal; $\mathbf{f}$ knotting of the 10-0 Prolene suture on the microcatheter tip; $g$ tensioning of the Prolene suture; $\mathbf{h}$ watertight suture of the scleral flap

complications are usually self-resolving, requiring no direct intervention.

\section{Intraoperative Complications}

A relatively frequent intraoperative complication of CP is the rupture of the trabeculo-descemetic membrane, especially at the beginning of the learning curve. From previous studies, rupture of the trabeculo-descemetic window has been reported in $1.8-8.5 \%$ of cases [34, 44, 45]. Micro-ruptures are generally not a problem, and the procedure may be completed as usual [34]. However, if a macro-perforation or iris prolapse is evident, it is advisable to convert the procedure to a penetrating surgery (i.e., TRAB).

Schlemm's canal cannulation cannot be completed in approximately $7.3-26 \%$ of cases because of anatomical anomalies of Schlemm's canal, trabecular meshwork scars or other reasons, but this percentage tends to decrease with experience [34, 44-46]. The microcatheter may stick at the entrance of a large collector channel, resisting the surgeon's attempts of advancement. In these cases it may be useful to slightly push over the distal tip of the catheter at the level of the limbus. If this is not useful, the catheter should be retracted, and the cannulation should be tried through the ostium 
opposite from Schlemm's canal. Creation of a false path and penetration of the microcatheter into the anterior chamber are exceptional intraoperative complications, and their incidence decreased with the surgeon's experience [41].

Descemet's membrane detachment is a rare but potentially vision-threatening complication $[47,48]$. Its frequency has been reported between $1.6 \%$ and $9.1 \%$ [44-46, 49]; however one case of bilateral Descemet's membrane detachment has been reported [34]. Descemet's membrane detachment happens when there is a strong adhesion between the inner and outer walls of Schlemm's canal, exceeding the resistance of the junction between Descemet's membrane and Schwalbe's line. Forcing viscoelastic material in these cases may cause a Descemet's membrane detachment. Descemet's membrane detachment is usually limited in size (1-2 mm) and resolves spontaneously. Rarely, it may extend until the visual axis, requiring additional intervention $[44,50]$.

\section{Postoperative Complications}

Microhyphaema is the most common postoperative complication of $\mathrm{CP}$ and is generally observable the 1st day after surgery. It has been reported in $6.1-85.2 \%$ of cases [34, 45, 46, 51]. Bleeding is considered a positive prognostic factor as it is due to blood reflux from the collector channels, indicating a patent and functioning outflow pathway [51]. Hyphaema is generally mild and resolves spontaneously in a few days or weeks from surgery.

IOP spikes in the days immediately following surgery have been reported in up to $30 \%$ of cases $[34,41,44-46,49,52-54]$. IOP spikes are probably due to remnants of viscoelastic material in Schlemm's canal, preventing AH outflow. IOP generally stabilizes $24-48 \mathrm{~h}$ after surgery, without the need for further intervention, when viscoelastic material has been completely reabsorbed. However, if IOP does not decrease spontaneously in $4-6$ weeks, it is advisable to perform a Nd:YAG-laser goniopuncture.

Laser goniopuncture creates a full-thickness opening in the trabeculo-descemetic window, converting the procedure in a penetrating surgery. In published studies, goniopuncture has been performed in up to $22 \%$ of patients in the 1 st year from surgery with good IOP control [32, 34, 44-47].

A transient decrease in visual acuity is a common finding during the first 2 weeks after surgery due to an induced with-the-rule astigmatism.

Cataract formation, a troubling complication especially in young subjects, has been described in $0-8.4 \%$ of patients who had previously undergone CP $[32,45,46]$. Compared with TRAB, for which cataract formation has been reported in approximately 50\% of cases [55-57], this percentage is far less. The effect of cataract extraction on eyes that have already undergone $\mathrm{CP}$ actually remains unknown. In a retrospective subgroup analysis of a larger sample of patients that previously underwent CP, Tetz et al. found a non-significant IOP reduction in 19 eyes after cataract extraction [52]. However, 4 of the 19 eyes (21.2\%) showed an increase in IOP $\geq 2 \mathrm{mmHg}$ at the first subsequent study visit.

Complications related to the Prolene suture are rare. Suture extrusion has been described in $0-6.7 \%$ of cases $[32,47,54]$, with no serious consequences. Uniformly distributed tension around the suture may decrease the risk of damage to the inner wall of Schlemm's canal and increase the strength of the trabecular meshwork related to suture tension.

A late IOP rise can be observed even years after a successful CP. In these cases, an ab interno stripping of the Prolene suture $[58,59]$ or a TRAB [60] should be performed.

\section{RESULTS}

Several studies have confirmed the short- and long-term hypotensive efficacy of CP. A multicentre study carried out at 15 clinical sites in US and Germany enrolled 157 patients affected by open-angle glaucoma (OAG), many of them on maximum tolerated medical therapy [46-48]. CP alone was performed on 122 patients (77.1\%), while CP combined with cataract surgery (phaco-canaloplasty, PCP) was performed 
on 36 patients (22.9\%). Follow-up examinations were scheduled at 1 day, 1 week and $1,3,6,12$, 18, 24, 30 and 36 months after surgery. Primary outcomes included IOP and glaucoma medications. At the 3-year follow-up visit, mean IOP for the entire group was $15.2 \pm 3.5 \mathrm{mmHg}$, and mean number of glaucoma medications was $0.8 \pm 0.9$ compared with a baseline IOP of $23.8 \pm 5.2 \mathrm{mmHg}$ and mean number of glaucoma medications of $1.5 \pm 1.0$. When only patients with successful suture positioning were evaluated (133 eyes, $84.7 \%$ ), IOP was found to be reduced by $34 \%$ and $42.1 \%$ in the CP and PCP group, respectively. IOP difference between the CP and PCP group was significant in all study visits $(p=0.095)$. High-resolution UBM images of the anterior segment were obtained from study eyes pre-, intra- and postoperatively. Suture-tensioning significantly influenced the IOP decrease at 24 months: patients with no evident tension at UBM examination had a $20 \%$ decrease in IOP from baseline and a 60\% reduction in medication use; patients with an observable tension had a $31 \%$ reduction in IOP and a $75 \%$ reduction in medication use [47].

A sub-analysis of the data from the previous study aimed to investigate the hypotensive efficacy of CP according to the surgical treatment received in three different groups of patients: group 1, CP in phakic eyes; group 2, $\mathrm{CP}$ in pseudophakic eyes; group 3, eyes having PCP [52]. At 3 years, IOP outcomes of group 1 (phakic eyes) and group 2 (pseudophakic eyes) were similar (mean IOP: $15.5 \pm 3.5$ and $15.6 \pm 3.5 \mathrm{mmHg}, \quad p=0.976$, respectively). Group 3 (PCP eyes) had significantly lower IOP values (mean IOP: $13.6 \pm 3.6 \mathrm{mmHg}$ ) than group $1(p=0.044)$, but similar to group 2 $(p=0.121)$. Mean number of medications at the 3 -year follow-up visit was significantly lower in group $3(0.3 \pm 0.5)$ compared with group 1 $(0.9 \pm 1.0, p<0.001)$ and group $2(1.1 \pm 0.8$, $p<0.001)$.

A European prospective multicentre study with a similar design was performed in Germany on 109 eyes of patients affected by OAG [45]. Inclusion criteria were a preoperative IOP of at least $16 \mathrm{mmHg}$ and an anamnestic IOP of at least $21 \mathrm{mmHg}$, with or without medical treatment. Ninety-three eyes underwent CP
(85.3\%) and 16 eyes underwent PCP (14.7\%). Successful positioning of the tension suture was achieved in 98 eyes (85.3\%). Mean baseline IOP was $23.0 \pm 4.3$ and $24.3 \pm 6.0 \mathrm{mmHg}$ in the CP and in the PCP group, respectively. At the 3-year follow-up visit, IOP was reduced by $34.3 \%$ (mean IOP: $15.1 \pm 3.1 \mathrm{mmHg}$ ) in eyes that underwent $\mathrm{CP}$ and by $43.2 \%$ (mean IOP: $13.8 \pm 3.2 \mathrm{mmHg}$ ) in eyes that underwent PCP $(p=0.22)$. Although IOP was constantly lower in the PCP group at all study visits, no significant difference between the two groups was reported.

Grieshaber et al. performed CP on 60 black African patients affected by advanced POAG, with a mean baseline IOP of $45.01 \pm 12.1 \mathrm{mmHg}$ [41]. CP was the first surgery for almost all the patients $(59 / 60)$. The complete success (i.e., without medications) rate of an IOP $\leq 21,18$ and $16 \mathrm{mmHg}$ was 81 , 67.8 and $47.2 \%$ at 36 months, respectively. Surgery outcome was not influenced by preoperative IOP, age or genre. The same author reported the results of a prospective study on 32 white OAG patients having $\mathrm{CP}$ as primary surgery [49]. Mean IOP was reduced from $27.3 \pm 5.6 \mathrm{mmHg}$ at baseline to $12.8 \pm 1.5 \mathrm{mmHg}$ at 12 months. When success was defined as an IOP $\leq 21,18$ and $16 \mathrm{mmHg}$, complete success was achieved in 93.8, 84.4 and $74.9 \%$ of eyes at 12 months, respectively. Nd:YAG-laser goniopuncture was performed in six eyes $(18.1 \%)$ when IOP exceeded the target of $16 \mathrm{mmHg}$. Partial Descemet membrane detachment occurred in two eyes during the surgery and in four eyes the microcatheter entered the suprachoroidal space. Both of these complications had no serious consequences.

In the study reported by Brusini, 256 patients affected by OAG and on maximum tolerated medical therapy underwent $\mathrm{CP}$, with a mean postoperative follow-up of $20.3 \pm 10.6$ months [34]. The full procedure could not be performed in 42 eyes $(16.4 \%)$ due to either a large perforation of the trabeculo-descemetic membrane with iris prolapse ( 2 eyes) or the impossibility of cannulating the full $360^{\circ}$ of Schlemm's canal (40 eyes). In these cases, anatomical obstacles and/or other intraoperative complications, such as the misdirection of the microcatheter into 
the anterior chamber, were the more frequent causes for aborting the procedure. Therefore, statistical analysis was performed on 214 eyes. Complete success criteria were defined as a postoperative IOP $\leq 21,18$ or $16 \mathrm{mmHg}$. Qualified success criteria were defined in the same manner; however medical therapy was allowed. Mean preoperative IOP was $29.4 \pm 7.9 \mathrm{mmHg}$. Complete success rates at 3-year follow-up were $44.8,31.0$ and $24.1 \%$ for the 21, 18 and $16 \mathrm{mmHg}$ criterion, respectively. Qualified success rates at 3-year follow-up were 86.2, 58.6 and $37.9 \%$, for the 21,18 and $16 \mathrm{mmHg}$ criterion, respectively. Number of glaucoma medications was $3.3 \pm 0.9$ before surgery and decreased to $1.3 \pm 1.5$ at 36 months.

The same author reported a multicentre interventional study in which 218 eyes from 197 OAG patients on maximum tolerated medical therapy underwent CP [44]. The full procedure could not be performed in 20 eyes $(9.2 \%)$ and consequently the statistical analysis was performed on 198 eyes from 178 patients. Criteria of complete and qualified success were defined as in the previous study. At 2-year follow-up visit, qualified success was obtained in $82(92.1 \%), 75(84.3 \%)$ and $61(68.5 \%)$ eyes for the 21,18 and $16 \mathrm{mmHg}$ criterion, respectively. Complete success was achieved in 63 (70.8\%), $60(67.4 \%)$ and $53(59.5 \%)$ eyes for the same criteria of success. Laser goniopuncture was performed in 18 eyes $(9.9 \%, 2-12$ months after surgery). Number of glaucoma medications decreased from $3.2 \pm 0.9$ before surgery to 1.1. \pm 1.3 at 2 -year visit.

In a retrospective study by Khaimi et al. 3-year results of CP performed on 277 OAG eyes were reported [61]. One hundred fifty eyes had $\mathrm{CP}$, while 127 eyes had PCP. Mean baseline IOP for the entire group, the CP group and PCP group was $19.7 \pm 6.7,21.1 \pm 7.2$ and $18.1 \pm 5.6 \mathrm{mmHg}$, respectively. After 36 months, mean IOP decreased to $15.2 \pm 4.3 \mathrm{mmHg}$ in the entire group, $15.0 \pm 4.6 \mathrm{mmHg}$ in the $\mathrm{CP}$ group and $15.4 \pm 4.0 \mathrm{mmHg}$ in the PCP group $(p<0.01$ for all the comparisons). When a success criterion of an $\mathrm{IOP}<15 \mathrm{mmHg}$ and a reduction $>25 \%$ from baseline was considered, $40.5 \%$ and $43.2 \%$ of eyes that had undergone
$\mathrm{CP}$ achieved the complete and qualified success at 36 months, respectively. However, only 7.4\% and $18.5 \%$ of eyes that had undergone PCP satisfied the same success criteria.

\section{COMPARISON WITH TRABECULECTOMY}

Several studies compared the efficacy and safety of $\mathrm{CP}$ with TRAB, the gold-standard procedure for glaucoma surgery [54, 62-66]. Generally, TRAB was more effective than CP in reducing IOP at the cost of a major rate of adverse events.

In a retrospective study, Ayyala et al. compared operative outcomes of CP and TRAB after a 12-month follow-up [62]. CP and TRAB plus mitomycin-C (MMC) were performed on 33 and 46 POAG eyes, respectively. Mean percentage decrease in IOP from preoperative values at 12 months was $32 \pm 22 \%$ in the CP group and $43 \pm 28 \%$ in the TRAB group $(p=0.072)$. When the success criterion was defined as an IOP $<18 \mathrm{mmHg}$ but $>4 \mathrm{mmHg}$, success was achieved in $87.9 \%(29 / 33)$ and $95.7 \%(44 / 46)$ of eyes in the $\mathrm{CP}$ and TRAB group, respectively. However, the difference was not significant $(p=0.23)$. Regarding complications, only hyphaema was more frequent in the $\mathrm{CP}$ than in the TRAB group $(21 \%$ vs. $2 \%$ of eyes, respectively, $p<0.01)$. Choroidal effusion (8 eyes), suprachoroidal haemorrhage ( 1 eye) and hypotony maculopathy (2 eyes) were reported only in the TRAB group.

Bruggemann et al. compared the efficacy and safety of $C P$ in one eye versus TRAB plus MMC in the contralateral eye in patients affected by OAG [63]. Thirty patients were included in this study. Mean preoperative IOP was $26.73 \pm 6.4$ and $26.3 \pm 10.9 \mathrm{mmHg}$ in eyes having $\mathrm{CP}$ and TRAB, respectively. Three eyes in the CP group (20\%) had a combined procedure of CP and cataract extraction. Mean IOP reduction at 12-month follow-up was $14.6 \pm 4.5$ $(50.3 \% \pm 10.5 \%)$ and $15.2 \pm 11.2 \mathrm{mmHg}$ $(53.4 \% \pm 20.1 \%)$ in the CP and TRAB eyes, respectively. The difference between the two groups was not significant $(p=0.87)$. In the CP group, a shallow hyphaema $<1.5 \mathrm{~mm}$ occurred in four eyes $(26.7 \%)$, a peripheral Descemet's 
membrane detachment in one eye (6.7\%) and a shallow anterior chamber in one eye $(6.7 \%)$, the 1 st day after surgery, requiring injection of viscoelastic material. In the TRAB group, two eyes (13.3\%) had a shallow anterior chamber immediately after surgery, requiring viscoelastic injection (one eye required four repeated injections), five eyes (33.3\%) had intermittent choroidal detachment and one eye (6.7\%) had hyphaema. Before the end of the study, two eyes (13.3\%) in the TRAB group required cataract extraction. Laser goniopuncture was performed only in one eye in the CP group.

Matlach et al. performed the first prospective randomized clinical trial comparing TRAB and CP [54]. The TVC (TRAB versus CP) study enrolled 62 patients affected by OAG, randomized to TRAB $(n=32)$ or CP $(n=30)$. Patients were followed up prospectively for 2 years. Criteria of success were defined as an IOP $\leq 18 \mathrm{mmHg}$ or an IOP reduction $\geq 20 \%$ from baseline (criterion 1) and as an IOP $\leq 21 \mathrm{mmHg}$ (criterion 2). Median baseline IOP was $20.0 \mathrm{mmHg}$ in the TRAB group and $22.0 \mathrm{mmHg}$ in the $\mathrm{CP}$ group $(p=0.06)$. When complete success (without medications) criteria were considered, the treatments of $23(74.2 \%)$ and $9(39.1 \%)$ patients were classified as successful according to criterion 1, and treatments of $21(67.7 \%)$ and $9(39.1 \%)$ patients were classified as successful according with criterion 2 in the TRAB and CP group, respectively, at 2 years. The difference between groups was significant for both the 18 and $21 \mathrm{mmHg}$ criterion ( $p=0.01$ for criterion 1 and $p=0.004$ for criterion 2). When qualified success (with or without medications) criteria were considered, treatments of $90.3 \%$ and $82.6 \%$ of patients were classified as successful according to criterion 1 and $96.8 \%$ and $82.6 \%$ were classified as successful according to criterion 2 in the TRAB and $\mathrm{CP}$ group, respectively. The difference between groups was significant only for criterion 2 $(p=0.01)$. Surgery-related adverse effects were more frequent in the TRAB group. Common complications of TRAB were transient hypotony $(37.5 \%)$, hypotony-related choroidal detachment (12.5\%), shallow anterior chamber (6.2\%), elevated IOP (25.0\%) and corneal erosion, probably due to 5 -fluorouracil (5FU) injections.
In the $\mathrm{CP}$ group, common complications were elevated postoperative IOP (>25 $\mathrm{mmHg}$ ) in $30 \%$ of patients and hyphaema in $23.3 \%$ of patients, which resolved spontaneously in the 1st postoperative week. More postoperative interventions were reported in the TRAB group as bleb management included 5FU injections, laser suturolysis and bleb needling.

Difference in hypotensive efficacy and safety between TRAB and CP has been evaluated in meta-analysis studies $[27,66]$. In the metaanalysis by Lin et al. on 215 patients from 4 previously published studies, mean difference in IOP between TRAB and CP at 12 months was $2.33 \mathrm{mmHg}$ (95\% CI: 0.66; 4.0, $p<0.01$ ) [66]. However, when a success criterion of IOP $<18 \mathrm{mmHg}$ was considered, no significant difference was found between TRAB and CP for both the complete (without medications, $p=0.19$ ) and qualified (with or without medications, $p=0.39$ ) successes. $\mathrm{CP}$ had a lower incidence of choroidal detachment than TRAB (OR: $0.12,95 \%$ CI: $0.03 ; 0.48, p<0.01$ ) and a higher incidence of hyphaema (OR: 8.80, 95\% CI: $2.25 ; 34.51, p<0.01)$. Fewer patients in the $\mathrm{CP}$ group than in the TRAB group had some other adverse events.

According to the meta-analysis by Zhang et al., TRAB was more effective than $\mathrm{CP}$ in reducing IOP by $3.65 \mathrm{mmHg}(95 \% \mathrm{CI}-6.42$; $-0.88, p=0.01$ ) at 12 months from surgery [65]. However, no significant difference between CP and TRAB was found regarding the reduction in medication number $(p=0.20)$. Comparing PCP with phaco-TRAB, phaco-TRAB showed a mean advantage of $4.02 \mathrm{mmHg}$ over CP $(95 \%$ CI $-7.62 ;-0.42, p=0.03)$ at 1 year. Difference in medication number was still not significant $(p=0.32)$. However, only two studies were included in this analysis. Hyphaema was more frequent in CP than TRAB (OR: 9.24, 95\% CI: $3.09 ; \quad 27.60, p<0.01)$. Descemet's membrane detachment was observed only in $\mathrm{CP}$, with a reported incidence of approximately $3 \%$. Hypotony (OR: 0.32 , 95\% CI $0.13 ; 0.80$, $p=0.01$ ) and choroidal effusion (OR: $0.25 ; 95 \%$ CI 0.06; 097, $p=0.04$ ) were complications with significantly fewer incidents in the CP group.

Quaranta et al. evaluated the increase in IOP during the postural change from sitting to 
supine position in a population of 52 POAG patients previously having successful TRAB $(n=26)$ or CP $(n=26)$ in one eye [64]. In each patient, sitting IOP measurement with a Goldmann applanation tonometer was followed by supine Perkins tonometry after 30 min of rest in the supine position. Mean postoperative sitting IOP was $10.2 \pm 2.3$ and $15.3 \pm 2.2 \mathrm{mmHg}$ in the TRAB and CP eyes, respectively $(p<0.01)$. In both cohorts supine IOP was significantly higher than sitting IOP $(p<0.01)$. In the CP eyes, the relative increase in IOP going from sitting to supine was $28.4 \%$ (absolute difference: $4.3 \pm 1.9 \mathrm{mmHg}$ ), whereas in the TRAB eyes it was $18.1 \%$ (absolute difference: $1.7 \pm 0.9 \mathrm{mmHg}$ ). The increase in IOP from the sitting to supine position was significantly greater in the CP group $(p<0.01)$ and similar to the one obtained in the contralateral non-operated eye (29.8\% in CP patients and $30 \%$ in TRAB patients). The authors concluded that the increase in IOP due to postural change is virtually not influenced by $\mathrm{CP}$, probably because Schlemm's canal surgery, differently from TRAB, aims to restore the physiological $A H$ outflow pathways.

\section{COMPARISON WITH OTHER NON- PENETRATING SURGERIES}

The main difference between $\mathrm{CP}$ and VC is that $\mathrm{CP}$ aims to re-open the entire Schlemm canal and not only a part of it [32]. Moreover, the positioning of a tensioning suture inside Schlemm's canal potentially reduces the risk of Schlemm's canal re-collapse in the long term. In a study by Koerber et al. the hypotensive efficacy of CP in one eye was compared with VC in the contralateral eye in a population of 15 patients affected by OAG [67]. Baseline mean IOP was $26.5 \pm 2.7$ and $24.3 \pm 2.8 \mathrm{mmHg}$ in the $\mathrm{CP}$ and VC eyes, respectively. $\mathrm{CP}$ achieved a significantly greater decrease in IOP $(\sim 12 \mathrm{mmHg})$ than $\mathrm{VC}(\sim 8 \mathrm{mmHg})$ at the 18-month follow-up visit $(p=0.02)$. However, the final absolute IOP was not significantly different between CP and VC $(14.5 \pm 2.6$ and $16.1 \pm 3.9 \mathrm{mmHg}$ for $\mathrm{CP}$ and $\mathrm{VC}$, respectively, $p=0.24)$. When the success criterion was defined as an IOP reduction $\geq 30 \%$ and an absolute value $<18 \mathrm{mmHg}, 86.7 \%$ and $60.0 \%$ of eyes in the CP group and $50 \%$ and $35.7 \%$ of eyes in the VC group achieved a qualified (with medications) and a complete (without medications) success, respectively.

Hypotensive efficacy and safety of CP and $\mathrm{VC}$ in POAG patients on maximum medical therapy were recently evaluated in a short-term follow-up study by Wagdy et al. [68]. In this study, 30 patients had CP with a baseline mean IOP of $27.2 \pm 1.9$ and 30 patients had VC with a baseline mean IOP of $26.4 \pm 2.95 \mathrm{mmHg}$. At 6 months from surgery, IOP was $15.6 \pm 1.2$ and $16.9 \pm 1.32 \mathrm{mmHg}$ in the CP and VC group, respectively. Fewer complications were generally reported for the CP than for the VC group. However, no direct comparison between the two groups was performed, so no clear conclusions can be drawn about these results.

PCP and phaco-DS were compared with a paper by Rekas et al. [69]. In this study, 29 eyes had PCP and 30 eyes had phaco-DS with a Healaflow implant for uncontrolled POAG. Mean IOP decreased from $19.0 \pm 6.9$ to $12.6 \pm 2.7 \mathrm{mmHg}$ and from $19.1 \pm 5.8$ to $14.3 \pm 3.5 \mathrm{mmHg}$ at 12 months in the PCP and phaco-DS group, respectively. No difference in IOP was found between the two groups $(p=0.107)$ at 12 months. Mean number of hypotensive medications was reduced from $2.64 \pm 0.68$ to $0.27 \pm 0.67$ in the PCP group and from $2.89 \pm 0.94$ to $0.55 \pm 0.94$ in the phaco-DS group. Again, no difference was found between the two groups $(p=0.304)$. PCP showed a higher incidence of postoperative hyphaema (58.6\% of eyes) and one case (3.4\%) of Descemet's membrane detachment. Both the hyphaema and Descemet's membrane detachment resolved spontaneously with no consequences. On average, 3.7 injections of $5 \mathrm{FU}$ per patient (range 1-10) were performed in the phaco-DS group, and 17 (56.6\%) eyes had goniopuncture.

In another study, the same group of authors reported on the results of a 24-month comparison between PCP and phaco-DS. In this study 37 eyes were randomized to receive PCP and 38 eyes to receive phaco-DS [70]. Quality of life (QoL) was evaluated by the means of the 
National Eye Institute Visual Function Questionnaire-25 items (NEI-VFQ-25). IOP decreased from $19.4 \pm 5.8 \mathrm{mmHg}$ preoperatively to $13.8 \pm 3.3 \mathrm{mmHg}$ at 24 months and from $19.7 \pm 5.4 \mathrm{mmHg} \quad$ preoperatively to $15.1 \pm 2.9 \mathrm{mmHg}$ at 24 months in the PCP and phaco-DS group, respectively. Starting from 6 months after surgery, IOP was significantly lower in the PCP group, and the difference remained significant until the 24-month visit $(p=0.04)$. After surgery, the NEI VFQ-25 mean composite score for PCP patients was $78.04 \pm 24.36$ points and for phaco-DS patients was $74.29 \pm 24.45$ points $(p=0.136)$. At 24 months, $68 \%$ of PCP eyes and $43 \%$ of phacoDS eyes did not require any glaucoma medication, although the difference in mean medication number between the two groups was not significant $(0.5 \pm 0.9$ and $1.1 \pm 1.2, p=0.058)$. Hyphaema was observed in 17 PCP eyes (46\%) and in all but one case resolved spontaneously. One case of peripheral Descemet's membrane detachment was reported in the PCP group. In the phaco-DS group, 36 eyes $(94.7 \%)$ received 5FU injections, 13 eyes (34\%) suture-lysis and 9 eyes (24\%) bleb needling. Nd:YAG-laser goniopuncture was performed in 14 (36.6\%) phaco-DS eyes and in 8 (22\%) PCP eyes.

\section{CONCLUSIONS}

$\mathrm{CP}$ is an effective and safe procedure to lower IOP in patients affected by OAG. Its advantages include no bleb formation, an easier follow-up and better safety profile compared with TRAB, which currently is the gold standard in glaucoma surgery. A target IOP around $15 \mathrm{mmHg}$ is easily achievable with this procedure, with or without the use of topical medications, and the association with cataract extraction may further reduce IOP. For these reasons, CP is mainly indicated in OAG patients who do not require a particularly low-target IOP regardless of the preoperative IOP values or in patients with significant risk factors for intra- or postoperative complications from TRAB. Disadvantages of this technique are extensive conjunctival and scleral manipulations that strongly limit the possibility of performing a subsequent TRAB, the long learning curve, the need for specific and expensive instrumentation and the unfeasibility in some patients due to anatomical limitations, angle closure or secondary glaucomas.

\section{ACKNOWLEDGEMENTS}

Funding. The contribution of Fondazione Bietti was supported by Fondazione Roma and the Italian Ministry of Health. No funding or sponsorship was received for this study or publication of this article.

Authorship. All authors had full access to all of the data in this study and take complete responsibility for the integrity of the data and accuracy of the data analysis. All named authors meet the International Committee of Medical Journal Editors (ICMJE) criteria for authorship for this article, take responsibility for the integrity of the work as a whole and have given their approval for this version to be published.

Disclosures. Ivano Riva reports consulting for Visufarma, Angelini and Glaucoom/Sooft outside the submitted work. Francesco Oddone reports consulting for Allergan, Centervue, Glaucoom, a grant from Allergan, Omikron, Glaucoom and Alfaintes, outside the submitted work. Robert N. Weinreb reports personal fees from Allergan, Alcon, Bausch + Lomb, Carl Zeiss Meditec, personal fees and non-financial support from Topcon, grants from Genentech, non-financial support from Optovue, grants from Quark and non-financial support from Heidelberg Engineering, outside the submitted work. Luciano Quaranta reports consulting and honoraria from Allergan, Omikron, Santen, Glaucoom/Sooft, Novartis and Visufarma, outside the submitted work. Paolo Brusini and Manuele Michelessi have nothing to disclose.

Compliance with Ethics Guidelines. This article is based on previously conducted studies and does not contain any studies with human participants or animals performed by any of the authors. 
Data Availability. Data sharing is not applicable to this article as no data sets were generated or analyzed during the current study.

Open Access. This article is distributed under the terms of the Creative Commons Attribution-NonCommercial 4.0 International License (http://creativecommons.org/licenses/ by-nc/4.0/), which permits any noncommercial use, distribution, and reproduction in any medium, provided you give appropriate credit to the original author(s) and the source, provide a link to the Creative Commons license, and indicate if changes were made.

\section{REFERENCES}

1. Tham YC, Li X, Wong TY, et al. Global prevalence of glaucoma and projections of glaucoma burden through 2040: a systematic review and meta-analysis. Ophthalmology. 2014;121:2081-90.

2. Giangiacomo A, Coleman A. Optic disc and visual field changes in primary open angle glaucoma. In: Grehn F, Stamper R, editors. Glaucoma. Berlin, Heidelberg: Springer; 2009. p. 13-21.

3. Goldberg I. Optic disc and visual field changes in primary open angle glaucoma. Aust J Ophthalmol. 1981;9:223-9.

4. De Moraes CG, Liebmann JM, Park SC, et al. Optic disc progression and rates of visual field change in treated glaucoma. Acta Ophthalmol. 2013;91:e86-91.

5. Pillunat LE, Stodtmeister R, Marquardt R, Mattern A. Ocular perfusion pressures in different types of glaucoma. Int Ophthalmol. 1989;13:37-42.

6. Quaranta L, Manni G, Donato F, Bucci MG. The effect of increased intraocular pressure on pulsatile ocular blood flow in low tension glaucoma. Surv Ophthalmol. 1994;38(Suppl):S177-81 (discussion S182).

7. Quaranta L, Katsanos A, Russo A, Riva I. 24-hour intraocular pressure and ocular perfusion pressure in glaucoma. Surv Ophthalmol. 2013;58:26-41.

8. Pillunat LE, Anderson DR, Knighton RW, Joos KM, Feuer WJ. Autoregulation of human optic nerve head circulation in response to increased intraocular pressure. Exp Eye Res. 1997;64:737-44.
9. Ojha P, Wiggs JL, Pasquale LR. The genetics of intraocular pressure. Semin Ophthalmol. 2013;28:301-5.

10. Gordon MO, Beiser JA, Brandt JD, et al. The Ocular Hypertension Treatment Study: baseline factors that predict the onset of primary open-angle glaucoma. Arch Ophthalmol. 2002;120:714-20 (discussion 829-730).

11. Miglior S, Torri V, Zeyen T, et al. Intercurrent factors associated with the development of open-angle glaucoma in the European glaucoma prevention study. Am J Ophthalmol. 2007;144:266-75.

12. Gordon MO, Ocular Hypertension Treatment Study G, European Glaucoma Prevention Study G, et al. Validated prediction model for the development of primary open-angle glaucoma in individuals with ocular hypertension. Ophthalmology. 2007;114:10-9.

13. Leske MC, Heijl A, Hussein M, et al. Factors for glaucoma progression and the effect of treatment: the early manifest glaucoma trial. Arch Ophthalmol. 2003;121:48-56.

14. The Advanced Glaucoma Intervention Study (AGIS): 7. The relationship between control of intraocular pressure and visual field deterioration.The AGIS Investigators. Am J Ophthalmol. 2000;130:429-440.

15. Musch DC, Gillespie BW, Niziol LM, et al. Intraocular pressure control and long-term visual field loss in the Collaborative Initial Glaucoma Treatment Study. Ophthalmology. 2011;118:1766-73.

16. Garway-Heath DF, Crabb DP, Bunce C, et al. Latanoprost for open-angle glaucoma (UKGTS): a randomised, multicentre, placebo-controlled trial. Lancet. 2015;385:1295-304.

17. Prum BE Jr, Rosenberg LF, Gedde SJ, et al. Primary open-angle glaucoma preferred practice pattern $((\mathrm{R}))$ guidelines. Ophthalmology. 2016;123:P41-111.

18. The European Glaucoma Society. Terminology and guidelines for glaucoma. 4th ed. Savona: PubliComm; 2014. p. 84-6.

19. Ariano ML, Ball SF. Delayed nonexpulsive suprachoroidal hemorrhage after trabeculectomy. Ophthalmic Surg. 1987;18:661-6.

20. Vaziri K, Schwartz SG, Kishor KS, et al. Incidence of postoperative suprachoroidal hemorrhage after glaucoma filtration surgeries in the United States. Clin Ophthalmol. 2015;9:579-84. 
21. Patel HY, Danesh-Meyer HV. Incidence and management of cataract after glaucoma surgery. Curr Opin Ophthalmol. 2013;24:15-20.

22. Zacharia PT, Deppermann SR, Schuman JS. Ocular hypotony after trabeculectomy with mitomycin C. Am J Ophthalmol. 1993;116:314-26.

23. Jampel HD, Musch DC, Gillespie BW, et al. Perioperative complications of trabeculectomy in the collaborative initial glaucoma treatment study (CIGTS). Am J Ophthalmol. 2005;140:16-22.

24. Susanna R Jr, Takahashi W, Nicolela M. Late bleb leakage after trabeculectomy with 5-fluorouracil or mitomycin C. Can J Ophthalmol. 1996;31:296-300.

25. The Fluorouracil Filtering Surgery Study Group. Three-year follow-up of the Fluorouracil Filtering Surgery Study. Am J Ophthalmol. 1993;115:82-92.

26. Yamamoto T, Sawada A, Mayama C, et al. The 5 -year incidence of bleb-related infection and its risk factors after filtering surgeries with adjunctive mitomycin C: collaborative bleb-related infection incidence and treatment study 2 . Ophthalmology. 2014;121:1001-6.

27. Rulli E, Biagioli E, Riva I, et al. Efficacy and safety of trabeculectomy vs nonpenetrating surgical procedures: a systematic review and meta-analysis. JAMA Ophthalmol. 2013;131:1573-82.

28. Eldaly MA, Bunce C, Elsheikha OZ, Wormald R. Non-penetrating filtration surgery versus trabeculectomy for open-angle glaucoma. Cochrane Database Syst Rev. 2014;15:CD007059.

29. Fyodorov S. Non penetrating deep sclerectomy in open-angle glaucoma. Eye Microsurg. 1989;2:52-5.

30. Stegmann R, Pienaar A, Miller D. Viscocanalostomy for open-angle glaucoma in black African patients. J Cataract Refract Surg. 1999;25:316-22.

31. Cameron B, Field M, Ball S, Kearney J. Circumferential viscodilation of Schlemm's canal with a flexible microcannula during non-penetrating glaucoma surgery. Digit J Ophthalmol. 2006;12:1.

32. Grieshaber MC. Viscocanalostomy and canaloplasty: ab externo Schlemm's canal surgery. Dev Ophthalmol. 2017;59:113-26.

33. Cagini C, Peruzzi C, Fiore T, et al. Canaloplasty: current value in the management of glaucoma. J Ophthalmol. 2016;2016:7080475.

34. Brusini P. Canaloplasty in open-angle glaucoma surgery: a four-year follow-up. ScientificWorldJournal. 2014;2014:469609.
35. Brusini P, Tosoni C, Zeppieri M. Canaloplasty in corticosteroid-induced glaucoma. Preliminary results. J Clin Med. 2018;7:31.

36. Lommatzsch C, Heinz C, Heiligenhaus A, Koch JM. Canaloplasty in patients with uveitic glaucoma: a pilot study. Graefes Arch Clin Exp Ophthalmol. 2016;254:1325-30.

37. Brusini P, Tosoni C. Canaloplasty after failed trabeculectomy: a possible option. J Glaucoma. 2014;23:33-4.

38. Korber N. Canaloplasty after trabeculectomy. Ophthalmologe. 2015;112:332-6.

39. Xin C, Chen X, Shi Y, Wang H, Wang N. Modified canaloplasty: a new, effective, and safe option for glaucoma patients with a disrupted schlemm canal wall. J Glaucoma. 2016;25:798-801.

40. Xin C, Chen X, Shi Y, et al. One-year interim comparison of canaloplasty in primary open-angle glaucoma following failed filtering surgery with primary canaloplasty. $\mathrm{Br} \mathrm{J}$ Ophthalmol. 2016;100:1692-6.

41. Grieshaber MC, Pienaar A, Olivier J, Stegmann R. Canaloplasty for primary open-angle glaucoma: long-term outcome. $\mathrm{Br} \mathrm{J}$ Ophthalmol. 2010;94:1478-82.

42. Godfrey DG, Fellman RL, Neelakantan A. Canal surgery in adult glaucomas. Curr Opin Ophthalmol. 2009;20:116-21.

43. Hamanaka $\mathrm{T}$, Kasahara $\mathrm{K}$, Takemura $\mathrm{T}$. Histopathology of the trabecular meshwork and Schlemm's canal in primary angle-closure glaucoma. Invest Ophthalmol Vis Sci. 2011;52:8849-61.

44. Brusini P, Caramello G, Benedetti S, Tosoni C. Canaloplasty in open-angle glaucoma: mid-term results from a multicenter study. J Glaucoma. 2016;25:403-7.

45. Bull H, von Wolff K, Korber N, Tetz M. Three-year canaloplasty outcomes for the treatment of openangle glaucoma: european study results. Graefes Arch Clin Exp Ophthalmol. 2011;249:1537-45.

46. Lewis RA, von Wolff $\mathrm{K}$, Tetz M, et al. Canaloplasty: three-year results of circumferential viscodilation and tensioning of Schlemm canal using a microcatheter to treat open-angle glaucoma. J Cataract Refract Surg. 2011;37:682-90.

47. Lewis RA, von Wolff $\mathrm{K}$, Tetz M, et al. Canaloplasty: circumferential viscodilation and tensioning of Schlemm canal using a flexible microcatheter for the treatment of open-angle glaucoma in adults: 
two-year interim clinical study results. J Cataract Refract Surg. 2009;35:814-24.

48. Lewis RA, von Wolff $\mathrm{K}$, Tetz M, et al. Canaloplasty: circumferential viscodilation and tensioning of Schlemm's canal using a flexible microcatheter for the treatment of open-angle glaucoma in adults: interim clinical study analysis. J Cataract Refract Surg. 2007;33:1217-26.

49. Grieshaber MC, Fraenkl S, Schoetzau A, Flammer J, Orgul S. Circumferential viscocanalostomy and suture canal distension (canaloplasty) for whites with open-angle glaucoma. J Glaucoma. 2011;20:298-302.

50. Gismondi M, Brusini P. Intracorneal hematoma after canaloplasty in glaucoma. Cornea. 2011;30:718-9.

51. Koch JM, Heiligenhaus A, Heinz C. Canaloplasty and transient anterior chamber haemorrhage: a prognostic factor? Klin Monbl Augenheilkd. 2011;228:465-7.

52. Tetz M, Koerber N, Shingleton BJ, et al. Phacoemulsification and intraocular lens implantation before, during, or after canaloplasty in eyes with open-angle glaucoma: 3-year results. J Glaucoma. 2015;24:187-94.

53. Fujita K, Kitagawa K, Ueta Y, et al. Short-term results of canaloplasty surgery for primary openangle glaucoma in Japanese patients. Case Rep Ophthalmol. 2011;2:65-8.

54. Matlach J, Dhillon C, Hain J, et al. Trabeculectomy versus canaloplasty (TVC study) in the treatment of patients with open-angle glaucoma: a prospective randomized clinical trial. Acta Ophthalmol. 2015;93:753-61.

55. Palanca-Capistrano AM, Hall J, Cantor LB, et al. Long-term outcomes of intraoperative 5-fluorouracil versus intraoperative mitomycin $C$ in primary trabeculectomy surgery. Ophthalmology. 2009;116:185-90.

56. Comparison of glaucomatous progression between untreated patients with normal-tension glaucoma and patients with therapeutically reduced intraocular pressures. Collaborative Normal-Tension Glaucoma Study Group. Am J Ophthalmol. 1998;126:487-497.

57. Wong TT, Khaw PT, Aung T, et al. The singapore 5-Fluorouracil trabeculectomy study: effects on intraocular pressure control and disease progression at 3 years. Ophthalmology. 2009;116:175-84.

58. Voykov B, Szurman P, Dimopoulos S, Ziemssen F, Alnahrawy O. Micro-invasive suture trabeculotomy after canaloplasty: preliminary results. Clin Exp Ophthalmol. 2015;43:409-14.

59. Seuthe AM, Januschowski K, Szurman P. Micro-invasive 360-degree suture trabeculotomy after successful canaloplasty-one year results. Graefes Arch Clin Exp Ophthalmol. 2016;254:155-9.

60. Voykov B, Rohrbach JM. Revision procedures after canaloplasty. Ophthalmologe. 2016;113:910-3.

61. Khaimi MA, Dvorak JD, Ding K. An analysis of 3 -year outcomes following canaloplasty for the treatment of open-angle glaucoma. J Ophthalmol. 2017;2017:2904272.

62. Ayyala RS, Chaudhry AL, Okogbaa CB, Zurakowski D. Comparison of surgical outcomes between canaloplasty and trabeculectomy at 12 months' follow-up. Ophthalmology. 2011;118:2427-33.

63. Bruggemann A, Despouy JT, Wegent A, Muller M. Intraindividual comparison of Canaloplasty versus trabeculectomy with mitomycin $\mathrm{C}$ in a single-surgeon series. J Glaucoma. 2013;22:577-83.

64. Quaranta L, Biagioli E, Riva I, et al. Effect of trabeculectomy and canaloplasty on intra-ocular pressure modifications after postural changes in open-angle glaucoma. Acta Ophthalmol. 2014;92:e498-9.

65. Zhang B, Kang J, Chen X. A system review and meta-analysis of canaloplasty outcomes in glaucoma treatment in comparison with trabeculectomy. J Ophthalmol. 2017;2017:2723761.

66. Lin ZJ, Xu S, Huang SY, Zhang XB, Zhong YS. Comparison of canaloplasty and trabeculectomy for open angle glaucoma: a Meta-analysis. Int J Ophthalmol. 2016;9:1814-9.

67. Koerber NJ. Canaloplasty in one eye compared with viscocanalostomy in the contralateral eye in patients with bilateral open-angle glaucoma. J Glaucoma. 2012;21:129-34.

68. Wagdy FM. Canaloplasty versus viscocanalostomy in primary open angle glaucoma. Electron Phys. 2017;9:3665-71.

69. Rekas M, Byszewska A, Petz K, Wierzbowska J, Junemann A. Canaloplasty versus non-penetrating deep sclerectomy - a prospective, randomised study of the safety and efficacy of combined cataract and glaucoma surgery; 12-month follow-up. Graefes Arch Clin Exp Ophthalmol. 2015;253:591-9.

70. Byszewska A, Junemann A, Rekas M. Canaloplasty versus nonpenetrating deep sclerectomy: 2-year results and quality of life assessment. J Ophthalmol. 2018;2018:2347593. 